\title{
EFICIÊNCIA DOS MERCADOS FUTUROS DE COMMODITIES AGRÍCOLAS APLICANDO- SE O TESTE DE COINTEGRAÇÃO
}

\author{
EFFICIENCY OF THE AGRICULTURAL \\ COMMODITY FUTURES MARKET BY \\ APPLYING THE COINTEGRATION TEST
}

\author{
Recebido 22/05/2012 \\ Aceito $27 / 07 / 2012$ \\ Jorge Harry Harzer ${ }^{1}$ \\ Carol Thiago Costa² \\ Wesley Vieira da Silva ${ }^{3}$ \\ Alceu Souza ${ }^{4}$
}

\section{RESUMO}

Este artigo tem o objetivo de testar a forma fraca de eficiência do mercado futuro brasileiro da commoditie agrícola café arábica, usando a técnica de cointegração a fim de verificar se os preços futuros correntes são estimadores não viesados dos preços à vista esperados para o futuro. Para isso, utiliza as séries históricas de janeiro de 2005 a maio de 2011 dos preços futuros, que foram coletados na Bolsa de Mercadorias e Futuros - BM\&F, e os preços à vista calculados pelo CEPEA/ESALQ/USP. As métricas utilizadas são os testes ADF de Dickey e Fuller para detectar a presença de raiz unitária e o teste de cointegração de Johansen para verificar a existência de um relacionamento de longo prazo. Os resultados indicaram a não estacionariedade das séries de preços e a presença de cointegração. Porém, o teste dos parâmetros $\alpha=0$ e $\beta=1$ da regressão que comprovam a eficiência fraca e não viés encontraram indícios estatísticos de não eficiência de mercado, bem como da presença de um viés indicando a existência de um prêmio associado ao risco.

Palavras-chave: Commoditie Agrícola; Mercado Futuro; Eficiência de Mercado; Cointegração

\footnotetext{
${ }^{1}$ Professor e Coordenador do Curso de Administração da Católica de Santa Catarina; Doutorando em Administração pela Pontifícia Universidade Católica do Paraná. E-mail: harzer@catolicasc.org.br

${ }^{2}$ Mestre em Administração pela Pontifícia Universidade Católica do Paraná. E-mail: ct.costa.adm@ibest.com.br

3 Professor do Programa de Pós-Graduação em Administração da Pontifícia Universidade Católica do Paraná. Doutor em Engenharia de Produção pela Universidade Federal de Santa Catarina, 2002. E-mail: wesley.vieira@pucpr.br

${ }^{4}$ Professor do Programa de Pós-Graduação em Administração da Pontifícia Universidade Católica do Paraná. Doutor em Administração de Empresas pela EASP, FGV São Paulo, 1996. E-mail: alceu.souza@pucpr.br
} 


\section{ABSTRACT}

This article aims at testing the weak form of efficiency of the commodity futures market in Arabica coffee farming using the cointegration technique in order to check if the current futures prices are biased estimators of spot prices expected for the future. Thereto it uses the futures prices time series from January 2005 to May 2011, which were collected in the Commodities and Futures Exchange-BM \& F and spot prices, calculated by CEPEA / ESALQ / USP. Dickey and Fuller's ADF tests are the metrics used to detect the presence of unit root and Johansen's cointegration test is used to verify the existence of a long term relationship. The results indicated the non-stationarity of price series besides the presence of cointegration. However, regression parameters testing $\alpha=0$ e $B=1$ proves that weak efficiency and non-biased found statistical evidence of non-market efficiency. Moreover, the presence of a bias indicating the existence of a premium associated with risk was also found.

Keywords: Agricultural commodity; Futures Market; Market Efficiency; Cointegration

\section{INTRODUÇÃO}

O agronegócio é uma atividade complexa e vulnerável a diversos fatores de riscos. Fatores climáticos, intensidade do papel intervencionista do estado, oscilações macroeconômicas, entre outros, representam algumas causas de riscos associadas a esse segmento da economia. Diante desse cenário de instabilidade, encontram-se os produtores rurais na ponta da oferta de seus produtos, e, do lado oposto, as indústrias que utilizam produtos agrícolas como matérias-primas, os atacadistas, os varejistas e os consumidores finais na condição de demandante de tais produtos.

Os mercados futuros podem ser utilizados como mecanismos de gerenciamento de riscos financeiros, seja para o mercado de ações, seja para as taxas de juros ou para os preços de commodities. Assim, os hedgers têm a possibilidade de transferir parte desses riscos aos especuladores que estejam dispostos a assumi-los mediante o recebimento de um prêmio. No agronegócio, o mercado futuro constitui-se uma forma de assegurar proteção aos riscos, o que possibilita ao produtor rural, que normalmente é a parte mais prejudicada em épocas de adversidades, programar suas atividades em termos da escolha do produto, da época do plantio, da área cultivada para cada produto, do nível de produção, dos estoques, etc., além de proteger seus investimentos e garantir a sobrevivência do negócio.

Além dessa capacidade de prover mecanismo de hedge, os mercados futuros podem oferecer a possibilidade de serem previsores de preços através dos contratos futuros das commodities negociadas. Porém, essa hipótese só é verdadeira se o mercado for eficiente. A hipótese de eficiência de mercado (HEM) parte da suposição de que os agentes do mercado futuro são racionais quanto às suas expectativas, são neutros ao risco e, portanto, os preços futuros não contemplam prêmio ao risco. A eficiência de mercado assume, ainda, que, na data de vencimento de um contrato, os preços à vista (spot) e futuro sejam convergentes. Com isso, acredita-se que os preços futuros no período corrente podem ser preditores não viesados dos preços à vista esperados para o futuro.

Sendo de fundamental importância para os agentes que visam proteger-se contra riscos de ordem financeira nos seus negócios, a temática envolvendo formas de se prever os preços à vista esperados no futuro é fonte de inúmeras possibilidades de exploração e estudo. Na agricultura, especificamente, a qual é fortemente influenciada por questões de diversas ordens, os riscos de perdas decorrentes das variações nos preços dos produtos são elevados. Nesse sentido, considerando-se tal diversidade, espera-se contribuir com uma discussão que lance novas perspectivas sobre o entendimento desse assunto. 
O objetivo deste trabalho é testar a forma fraca de eficiência do mercado futuro brasileiro para a commoditie café arábica, usando-se da técnica de cointegração para verificar se os preços futuros correntes são estimadores não viesados dos preços à vista esperados para o futuro no período compreendido entre 01/01/2005 a 31/05/2011. Os dados secundários utilizados para os preços futuros foram coletados na Bolsa de Mercadorias e Futuros - BM\&F, e os preços à vista utilizados como proxy são os índices da ESALQ/BM\&F, calculados pelo CEPEA/ESALQ/USP. As métricas utilizadas são os testes ADF de Dickey e Fuller para detectar a presença de raiz unitária e o teste de cointegração de Johansen para verificar a existência de um relacionamento entre as variáveis no longo prazo.

A escolha da commoditie café arábica deve-se ao fato de ser um produto com grande volume de negociação em número de contratos no mercado futuro, perdendo apenas para o boi gordo. Em 2010, foram negociados mais de 600 mil contratos futuros do café arábica, representando $28 \%$ do total negociado.

O trabalho está dividido nas seguintes seções: 1) introdução; 2) referencial teórico, apresentado conceitos sobre derivativos, eficiência de mercado e formação dos preços no mercado futuro; 3 ) metodologia, englobando a descrição da pesquisa, a coleta e o tratamento dos dados; 4) apresentação e análise dos dados; e, por fim 5) considerações finais.

\section{REFERENCIAL TEÓRICO}

\subsection{Derivativos}

Amaral (2003) descreve que a história dos derivativos começou por volta do século XVII, com os contratos agrícolas. $O$ autor relata que, naquela época, compradores e vendedores negociavam as quantidades, os preços em que os bens seriam transacionados e a data futura de liquidação, que se dava através da entrega física dos produtos. Essas transações ocorriam em lugares específicos, compreendendo, assim, uma espécie de bolsa rudimentar. Segundo Amaral (idem), por volta de 1730, surgiu a primeira bolsa organizada - a Bolsa de Arroz de Osaka. Em 1898, surgiu a Chicago Mercantile Exchange e, desde aquela época, outras Bolsas foram surgindo pelo mundo. No Brasil, a Bolsa de Mercadorias e Futuros - BM\&F foi constituída em 1985, sendo que, até os dias de hoje, vem crescendo em termos de derivativos disponíveis e em número de transações.

Derivativos, como o próprio nome indica, são títulos cujo valor deriva do preço de outro ativo e são usualmente utilizados como mecanismo de gerenciamento de riscos provocados pela oscilação dos preços desses ativos no mercado. São divididos em financeiros e não financeiros. Financeiros são aqueles relacionados com taxas de juros, moedas, índices de Bolsa, etc. Não financeiros são os associados às commodities em geral, tais como, açúcar, café, soja, milho, etc.

Autores como Figueiredo (2002), Bessada, Barbedo e Araújo (2007), entre outros, destacam os agentes econômicos que operam com os derivativos. Para eles, há o hedger, cujo principal objetivo é o de se proteger contra as variações dos preços, buscando reduzir seus riscos; o especulador, participante que busca obter ganhos com a compra e venda de derivativos, apostando em tendências, nos valores segundo suas crenças de alta ou de baixa, assumindo os riscos transferidos dos hedgers; e o arbitrador, cujo propósito é o de obter ganhos com as distorções de preços entre dois mercados distintos, comprando o derivativo no local mais barato e simultaneamente vendendo-o no local em que o mesmo esteja mais caro.

Os tipos de derivativos mais comuns são: contratos futuros, de opções, e operações de swap. Contratos futuros são aqueles instrumentos derivativos que obrigam as partes envolvidas a entregarem ou receberem uma determinada quantidade de um ativo, a um preço pré- 
determinado, numa data específica. Opções são contratos que permitem o direito de comprar ou de vender determinado ativo por um preço certo, em determinada data. Diferem dos contratos futuros à medida que os contratos de opções não representam compromissos firmes e definitivos, conferem, ao seu titular, um direito e não uma obrigação de comprar ou vender o ativo. Já as operações de swap são operações em que as partes trocam de indicadores entre operações ativas e passivas, sem trocar o principal.

Barros e Lopes (2006), ao descrever os contratos futuros, destacam que estes são diferentes dos contratos a termo, já que os primeiros são contratos padronizados, contam com prazos e garantias definidos e são negociados em bolsa. Já os contratos a termo são negociados no mercado de balcão, fora dos mercados organizados. Os autores destacam, também, a presença da Clearing House, a câmara de compensação da bolsa, responsável pela liquidação dos contratos, o que garante credibilidade ao sistema. Por outro lado, no mercado a termo, há o risco de as partes não cumprirem o compromisso assumido, pois estes não são negociados em bolsas.

No mercado futuro, todos os contratos têm seus preços ajustados diariamente, mantendo-os aos valores de mercado. De acordo com Bessada, Barbedo e Araújo (2007), preço futuro e preço à vista tendem a se convergir, embora não necessariamente na mesma magnitude e no mesmo tempo. Para os autores, a base tende à zero na medida em que se esgota o prazo para o vencimento do contrato, ou seja, o preço futuro converge para o preço à vista, pois, na data do vencimento, o contrato deve ser liquidado, apresentando as mesmas características do produto no mercado à vista naquela data.

Para Marques e Mello (1999), a base corresponde à diferença entre o preço de uma commoditie no mercado físico e sua cotação no mercado futuro. Em outras palavras, corresponde ao custo de se manter a posse física da mercadoria até a data do vencimento do contrato futuro. É positiva e no máximo igual aos custos de armazenamento, somados juros, seguros, despesas de carga e descarga, e margem de lucro do vendedor (BESSADA; BARBEDO; ARAÚJO, 2007). Na concepção de Zilio (apud AMADO; CARMONA, 2004), em se tratando do mercado de derivativos, o estudo do comportamento da base é de fundamental importância para a tomada de decisões dos investidores em geral, uma vez que, quanto mais correta a previsão da base futura, menor o risco e maior a probabilidade de que o hedger consiga obter sucesso.

\subsection{Hipótese da eficiência de mercado}

O conceito de eficiência de mercado tem origem na teoria econômica. Segundo esse conceito, eficiência requer que uma atividade seja conduzida a um nível em que o custo marginal iguala ao benefício marginal (WONNACOTT; WONNACOTT, 1982). Em finanças corporativas, o conceito se estende para hipótese de mercados eficientes, segundo o qual os títulos (ações, commodities, etc.) estão sempre em equilíbrio, ou seja, têm um preço que é justo e reflete toda informação publicamente disponível em cada título (WESTON; BRIGHAM, 2000).

Vários estudos relatam que a hipótese da eficiência de mercado (HEM) foi originalmente concebida por Fama (1970), segundo o qual, em um mercado eficiente, os preços dos títulos sempre refletem toda informação disponível e a única mudança que pode ocorrer resulta de nova informação. Nesse sentido, Malkiel (2003) afirma que, quando surge uma informação, a notícia se espalha muito rapidamente e é incorporada aos preços dos títulos sem demora. Ainda segundo o autor, nenhuma análise técnica, nem mesmo fundamentalista, ajuda os investidores, permitindo-os obter retornos superiores aos que poderiam ser obtidos mediante a realização de um portfólio com risco comparável selecionado aleatoriamente. 
O estudo de Fama (1970) relata que há três condições suficientes para que a HEM se verifique: inexistência de custos de transação nas negociações dos títulos; todas as informações são disponibilizadas sem custos para os participantes do mercado; e concordância geral nas expectativas dos investidores, quanto aos efeitos das informações sobre os preços atuais e futuros dos títulos. Fama (1970) destaca, ainda, três formas de eficiência:

- Fraca: as informações de preços passados não são úteis para se conseguir retornos anormais;

- Semiforte: nenhum investidor pode obter retornos anormais com base nas informações públicas, pois os preços se ajustam rapidamente às novas informações divulgadas;

- Forte: nenhum investidor poderia obter retornos anormais, mesmo utilizando-se de informações confidenciais ainda não publicadas, já que o ajuste dos preços no mercado é instantâneo.

Para Carvalho, Giachero e Ribeiro (2007), a eficiência de mercado se fundamenta em três hipóteses sobre a racionalidade dos investidores: 1 ) todos os investidores são racionais e, portanto, avaliam os títulos racionalmente; 2 ) nem todos os investidores são racionais, o que significa que suas negociações com títulos são aleatórias e, portanto, eliminam umas às outras sem alterar os preços dos títulos; 3 ) os investidores são irracionais, mas a presença de arbitradores eliminaria a influência de tais investidores no preço dos títulos.

Malkiel (2003) destaca que os mercados financeiros podem ser eficientes mesmo que às vezes sejam feitos erros em sua avaliação, mesmo que muitos participantes do mercado sejam absolutamente irracionais, mesmo que os preços dos títulos apresentem maior volatilidade do que aparentemente, por conceitos básicos, tais como lucro e dividendos para as ações. $O$ autor acrescenta que muitos economistas acreditam na eficiência porque veem o mercado como dispositivo incrivelmente bem sucedido para refletir novas informações rapidamente e, em grande parte, com precisão. Malkiel (idem) complementa enfatizando que, acima de tudo, esses economistas acreditam na eficiência dos mercados financeiros porque estes não permitem aos investidores ganhar retornos sem riscos acima da média.

Em síntese, mercado eficiente é aquele que incorpora aos preços dos títulos toda informação disponível, considera que os investidores são racionais e neutros em relação ao risco. Em outras palavras, os mercados eficientes não permitem aos investidores obter retorno acima da média sem aceitar riscos (MALKIEL, 2003). Satisfazendo essas condições, a forma fraca de eficiência pressupõe que os preços futuros correntes são preditores não viesados dos preços à vista esperados para o futuro para um determinado título.

\subsection{Formação dos preços no mercado futuro}

De acordo com estudos realizados por Amado e Carmona (2003), a formação dos preços nos mercados futuros das commodities exige a suposição de que não exista a possibilidade de arbitragem. Não pode haver discrepâncias entre o preço esperado para a data do vencimento e o preço spot nesta mesma data. Diante desse conceito, manter a posse física de um ativo tem o mesmo valor que assumir uma posição comprada em um contrato futuro do mesmo tipo de ativo até o vencimento do contrato. Isso implica a seguinte equação: 


$$
F=(S+U) e^{r t}
$$

Na equação (1), $F$ representa o preço futuro do ativo; $S$ é o preço corrente; $U$, o custo de armazenagem, e $e^{r t}$, a ponderação da taxa de juros livre de risco $(r)$ pelo tempo $(t)$ para que a mercadoria seja entregue pelo contrato futuro.

De acordo com essa relação, $F$ não pode ser inferior a $(S+U)$, o que não incentivaria a produção de uma commoditie ou a sua compra no mercado à vista, além de permitir a geração de ganho por quem detivesse essa mercadoria em caso de escassez temporária. É necessário que se tenha uma situação de equilíbrio, gerando o que Hull (2005) chama de convenience yield, que, em outras palavras, reflete as expectativas do mercado quanto à disponibilidade futura de uma commoditie. O convenience yield pode subir quando ocorre a possibilidade de ocorrer escassez durante a vida do contrato futuro ou diminuir se os usuários dessa commoditie possuírem estoques elevados.

Conforme descrito na seção 2.1, a base corresponde à diferença entre o preço de uma commoditie no mercado físico e sua cotação no mercado futuro, ou seja, é o custo de se manter a posse física de um produto até a data de vencimento do contrato futuro. Assim, quanto mais próximo à data do vencimento do contrato futuro, mais baixa será a base. Como consequência, há a tendência de, ao longo do tempo, o preço futuro se aproximar do preço à vista, ou seja, convergem-se ao longo desse tempo. Diante disso, diz-se que o preço futuro no período corrente seria um previsor não viesado do preço à vista esperado no futuro. De acordo com Amado e Carmona (2003), essa capacidade que os preços futuros no presente têm de estimar os preços à vista no futuro pode ser representada da seguinte forma:

$$
F_{T-n}=E\left(S_{T}\right)
$$

$E\left(S_{T}\right)$ representa a esperança de preço na data de vencimento do contrato; $F_{T-n,}$ o preço futuro na data $T$ - $n$; e $n$, o número de períodos antes do vencimento.

Conforme descrito na seção anterior, a hipótese de eficiência de mercado considera, entre outros fatores, que os preços futuros no período corrente são preditores não viesados dos preços à vista esperados no futuro, sem incorporar um prêmio ao risco. No caso da incorporação de um prêmio de risco, normalmente exigido pelos especuladores, essa relação, conforme Amado e Carmona (2003) ficaria:

$$
F=E\left(S_{T}\right) e^{(r-k) T}
$$

Em que, nesse caso, $k$ seria a taxa de desconto dependente do risco sistemático. Entretanto, a HEM desconsidera a existência de prêmio associada ao risco. Dessa forma, o teste de eficiência de mercado na forma fraca, conforme Back (1994) e Fama (1970) (apud MELO; LIMA; MORAES, 2006), seria descrito pela equação:

$$
S_{t+1}=c_{0}+c_{1} F_{t}+\varepsilon_{t+1}
$$

Em que $S_{t+1}$ é o preço à vista esperado para o futuro, $F_{t}$ é o preço futuro no período corrente do contrato da commoditie, $c_{0}$ e $c_{1}$ são parâmetros e $\varepsilon_{t+1}$ é um termo aleatório de erro identicamente distribuído com média zero e variância constante. Ainda de acordo com a HEF, os parâmetros $c_{0}$ e $c_{1}$ são iguais a zero e um, respectivamente, pois $c_{0}$ representa a neutralidade 
ao risco e $c_{1}$ toda informação disponível que o $F_{t}$ possui para prever o preço à vista no futuro. Assumir a existência de um prêmio de risco significa que $c_{0}$ seja diferente de zero.

Logo, para se aplicar a regressão apresentada acima (4), é preciso testar as restrições dos parâmetros $c_{0}=0$ e $c_{1}=1$, indicando uma previsão não viesada. É possível a realização de testes conjuntos dessas restrições ou em separado para cada uma delas. A restrição $c_{1}=1$ é o indicador mais importante, pois $c_{0}$ diferente de zero implica presença de prêmio ao risco.

\section{METODOLOGIA}

No presente trabalho, seguiu-se a classificação proposta por Jung (2003) no que diz respeito à sua organização. Assim sendo, quanto à sua natureza, este estudo caracteriza-se como uma pesquisa aplicada, uma vez que o mesmo visa, a partir do processo de pesquisa, gerar novos conhecimentos sobre a temática escolhida (JUNG, 2003).

Quanto aos seus objetivos, o estudo pode ser classificado como exploratório e descritivo. Exploratório, porque almeja levantar informações acerca de um objeto específico, no caso, as formas de se prever os preços à vista esperados no futuro, delineando as condições de manifestação do mesmo. Descritivo, por identificar, registrar e analisar as características, fatores ou variáveis relacionados ao objeto de estudo em questão, conforme ensina Jung (2003).

Para a coleta de dados, utilizou-se a pesquisa bibliográfica, identificando-se algumas das produções já existentes acerca do tema e a pesquisa documental, materializada através dos relatórios que serviram como base para levantamento dos dados a serem analisados (Jung, 2003). Tanto as premissas da abordagem qualitativa quanto da abordagem quantitativa foram utilizadas, buscando-se, desta forma, a efetivação de uma análise mais abrangente dos dados coletados.

\subsection{DESCRIÇÃO DOS DADOS}

Os preços vigentes no mercado futuro foram obtidos junto à Bolsa de Mercadorias e Futuros - BM\&F da BMF\&BOVESPA. Estes são cotados em dólares dos Estados Unidos da América por saca de 60 quilos, livre de impostos e para entrega no município de São Paulo. Foram coletados os preços futuros negociados nos pregões de 03 de janeiro de 2005 a 11 de maio de 2011, e calculadas as médias das cotações diárias das operações realizadas para cada vencimento futuro, que ocorre todos os anos nos meses de março, maio, julho, setembro e dezembro, obtendo-se, dessa forma, 32 observações dentro desse período.

Os preços no mercado à vista foram obtidos junto ao Centro de Estudos Avançados em Economia Aplicada-CEPEA/ESALQ da Universidade de São Paulo. Estes são calculados diariamente pelo CEPEA, através da média ponderada das cotações das principais regiões produtoras do País, em moeda nacional, e convertidos em dólares dos Estados Unidos da América. Assim, foram utilizados os preços à vista vigentes nas datas dos vencimentos dos contratos futuros.

No entanto, convém destacar que o período compreendido na análise dos dados abrange uma longa crise financeira internacional, que teve seu auge no segundo semestre de 2008. Essa crise não só levou à falência várias instituições financeiras pelo mundo, mas também ameaçou fortemente o sistema financeiro mundial. É possível, ainda, que seus efeitos tenham afetado o mercado de commodities, como o café, cujo preço é influenciado pelo comportamento do mercado internacional. Embora não se note grandes oscilações nos preços à vista e futuro a partir de setembro de 2008, época do estouro da crise, é possível que esse fator limite ou até mesmo invalide a hipótese de eficiência de mercado, constituindo, assim, uma limitação nos resultados apresentados. 


\subsection{TRATAMENTO DOS DADOS}

As técnicas utilizadas para verificar a eficiência de mercado foram os testes de raízes unitárias ADF de Dickey e Fuller $(1979,1981)$ e de cointegração de Johansen. A constatação da eficiência no mercado brasileiro de café é determinada quando, entre os Preços Futuros e os Preços à Vista, há cointegração, ou seja, as variáveis mantém uma relação linear de longo prazo.

\subsubsection{Teste de Raízes Unitárias ADF}

O procedimento utilizado para verificar a estacionariedade das variáveis - Preços Futuros (PF) e Preços à Vista (PV) - foi o teste ADF de Dickey e Fuller (1979; 1981), o qual foi realizado por meio do software PC Give.

Considerando-se o seguinte modelo:

$$
Y_{t}=\rho Y_{t-1}+\varepsilon_{t}
$$

em que $\varepsilon_{t}$ é ruído branco. Dessa forma, testa-se que $\mathrm{H}_{0}: \rho=1$ contra a $\mathrm{H}_{\mathrm{a}}: \rho<1$. Caso $|\rho|<1, Y_{t}$ é estacionário e descrito como um processo AR (1). De outra forma, caso $\rho=1, Y_{t}$ é não estacionário e descrito como um modelo de passeio aleatório. Esse modelo pressupõe a existência da tendência, porém sem a existência do intercepto.

Para o modelo com intercepto, a equação assume a seguinte forma:

$$
Y_{t}=\alpha+\rho Y_{t-1}+\varepsilon_{t}
$$

Já o modelo com intercepto e tendência tem a seguinte forma:

$$
Y_{t}=\alpha+B t+\rho Y_{t-1}+\varepsilon_{t}
$$

O objetivo do teste de Dickey-Fuller é testar a existência de raiz unitária em $Y_{t}$ nas equações (5), (6) e (7), sob a hipótese da não existência de autocorrelação nos resíduos.

Subtraindo-se $Y_{t-1}$ em ambos os lados das três equações, tem-se:

$$
\begin{aligned}
& \Delta Y_{t}=y Y_{t-1}+\varepsilon_{t} \\
& \Delta Y_{t}=\alpha+y Y_{t-1}+\varepsilon_{t} \\
& \Delta Y_{t}=\alpha+b \mathrm{t}+y Y_{t-1}+\varepsilon_{t}
\end{aligned}
$$

sendo $y=\rho-1$.

Dessa maneira, testar a hipótese de que $\rho=1$ seria o mesmo que testar $y=0$ contra a hipótese alternativa de que $y<1$. Utiliza-se o processo de estimação de mínimos quadrados ordinários para a realização do teste.

É importante destacar que o teste de raiz unitária não utiliza a distribuição padrão $t$ de Student, mas sim a estatística $\tau$, cujos valores críticos foram tabulados por Fuller (1976) com base em simulações de Monte Carlo. Quando da presença de intercepto, a estatística é chamada $\tau_{\mu}$, e, para raiz unitária na presença de intercepto e tendência, a estatística utilizada é a $\boldsymbol{\tau} \tau$.

O teste de Dickey-Fuller tem suas hipóteses descritas da seguinte forma: 
$\mathrm{H}_{0}$ : Preço Futuro (PF) tem uma raiz unitária, ou seja, a série é não estacionária (apresenta tendência em sua série histórica);

$\mathrm{H}_{1}$ : Preço Futuro (PF) não tem raiz unitária, ou seja, a série é estacionária (não apresenta tendência em sua série histórica).

$\mathrm{H}_{0}$ : Preço a Vista (PV) tem uma raiz unitária, ou seja, a série é não estacionária (apresenta tendência em sua série histórica);

$\mathrm{H}_{1}$ : Preço a Vista (PV) não tem raiz unitária, ou seja, a série é estacionária (não apresenta tendência em sua série histórica);

Uma vez verificada a estacionariedade das variáveis, o procedimento seguinte é aplicar o teste de cointegração do Johansen. Esse procedimento é descrito como segue.

\subsubsection{Teste de cointegração de Johansen}

A aplicação do teste de cointegração permite verificar se duas ou mais variáveis são sincronizadas. Ocorrendo que as séries temporais sejam cointegradas, significa que os parâmetros resultantes das regressões não são espúrios, e há relação de equilíbrio de longo prazo entre elas (JOHANSEN, 1991, 1995). A verificação da existência de cointegração entre os preços futuro e à vista do café requer que os testes aplicados estejam de acordo com as etapas a seguir descritas. Inicialmente, é aplicado o teste ADF (Augmented Dickey-Fuller) para verificar se as séries temporais dos preços futuros e preços à vista do café são I(1) (Integradas de Ordem 1) e, portanto, atendem a condição necessária para a cointegração (GUJARATI, 2006). Na sequência, aplica-se o método proposto por Johansen (1988) e Johansen e Juselius (1990), baseado no procedimento de estimação por máxima verossimilhança, a seguir, resumidamente desenvolvido: seja um VAR (Vetor Auto Regressivo) de ordem $p$, tal que:

$$
Y_{\mathrm{t}}=A_{1} Y_{t-1}+A_{2} Y_{\mathrm{t}-2}+A_{\mathrm{p}} Y_{\mathrm{t}-\mathrm{p}}+u_{\mathrm{t}}
$$

sendo $Y_{t}$ um vetor $k \times 1$ de variáveis não-estacionárias I(1), $x_{t}$ é um vetor de variáveis determinísticas, e $u_{\mathrm{t}}$ é um vetor de erros aleatórios. Esse $\operatorname{VAR}(p)$ pode ser reescrito como:

$\Delta y_{\mathrm{t}}=\prod \mathrm{y}_{\mathrm{t}-1}+\Pi=\sum_{i=1}^{p} \mathrm{~A}_{j}-\mathrm{I}$

com

$\Pi=\sum_{i=1}^{p} \mathrm{~A}_{j}-\mathrm{I} \quad \Gamma_{i}=-\sum_{j=i+1}^{p} \mathrm{~A}_{j}$

Conforme o teorema de representação de Granger, se a matriz dos coeficientes $\Pi$ tem rank reduzido $r<k$, então, existem $k \times r$ matrizes $\alpha$ e $\beta$, ambas com rank $r$, tais que $\Pi=\alpha \beta^{\prime}$ e $\beta^{\prime} y t \sim \mathrm{I}(0)$, sendo $r$ o número de relações de cointegração (o rank de cointegração), e cada coluna de $\beta$ é um vetor de cointegração. Os elementos de $\alpha$ são conhecidos como os parâmetros de ajustamento do modelo de correção de erros. $O$ teste de Johansen consiste em estimar a matriz $\Pi$ a partir de um VAR irrestrito e testar se é possível rejeitar as restrições implícitas ao 
rank reduzido de $\Pi$ (QMS, 2004). Continuando-se, na proposição de Johansen e Juselius (1990), e Johansen (1991), os testes de hipóteses para verificar o número de raízes características da matriz $\Pi$, estatisticamente diferentes de zero, tiveram suas distribuições assintóticas derivadas, com uma delas convergindo para o traço da matriz e a outra para o autovalor máximo da matriz. Assim, a estatística do teste de razão de verossimilhança para verificar a hipótese nula "existência de no máximo $k$ vetores cointegrantes" contra a alternativa "número desses vetores é maior do que $k^{\prime \prime}$ é dada pela estatística do traço designada em (14).

$$
\lambda_{\text {trace }}(k)=-\mathrm{T} \sum_{i=k+1}^{n} \ln \left(1-\hat{\lambda}_{i}\right)
$$

Na equação (14), $\lambda_{i}$ é a estimativa das raízes características (ou autovalores) obtidos da matriz $\Pi$, e $T$ é o numero de observações. A estatística do teste de razão de verossimilhança para verificar a hipótese nula "existência de exatamente $k$ vetores cointegrantes" contra a alternativa "número desses vetores é igual a $k+1$ " é dada pela estatística do autovalor máximo, tal como pode ser visto em (15).

$$
\lambda_{\max }(\mathrm{k}, k+1)=-\mathrm{T} \ln \left(1-\hat{\lambda}_{k+1}\right)
$$

Johansen e Juselius (1990) fornecem valores críticos para (14) e (15) em três situações distintas, dependendo dos termos deterministas que aparecem em (12).

Para que a eficiência no mercado de café brasileiro seja evidenciada, é preciso que as séries Preço Futuro e Preço à Vista sejam cointegradas. Dessa maneira, o teste de Johansen tem descritas as seguintes hipóteses:

$\mathrm{H}_{0}$ : Preço Futuro (PF) e Preço à Vista (PV) são não cointegrados, isto é, o mercado de café não se apresenta eficiente;

$\mathrm{H}_{1}$ : Preço Futuro (PF) e Preço à Vista (PV) são cointegrados, isto é, o mercado de café apresenta-se eficiente.

A seção seguinte apresenta os resultados da análise econométrica realizada.

\section{APRESENTAÇÃO E ANÁLISE DOS DADOS}

O café arábica é o segundo produto mais negociado em volume de contratos futuros na BM\&F. Fato que demonstra sua grande importância econômica. Segundo a Companhia Nacional de Abastecimento - CONAB, no biênio 2010/11, a safra cafeeira do Brasil ultrapassou 48,09 milhões de sacas de 60 quilos do produto beneficiado. A cada biênio, a produção oscila muito, sobretudo por questões climáticas. Ainda assim, a safra do último biênio foi 21,9\% superior a de 2009/10 e 53,7\% superior a de 2001/02. Minas Gerais é o Estado com maior produção, responsável, em 2010/11, por $52,3 \%$ da produção nacional, seguido pelo Espírito Santo, com 21,1\%. 


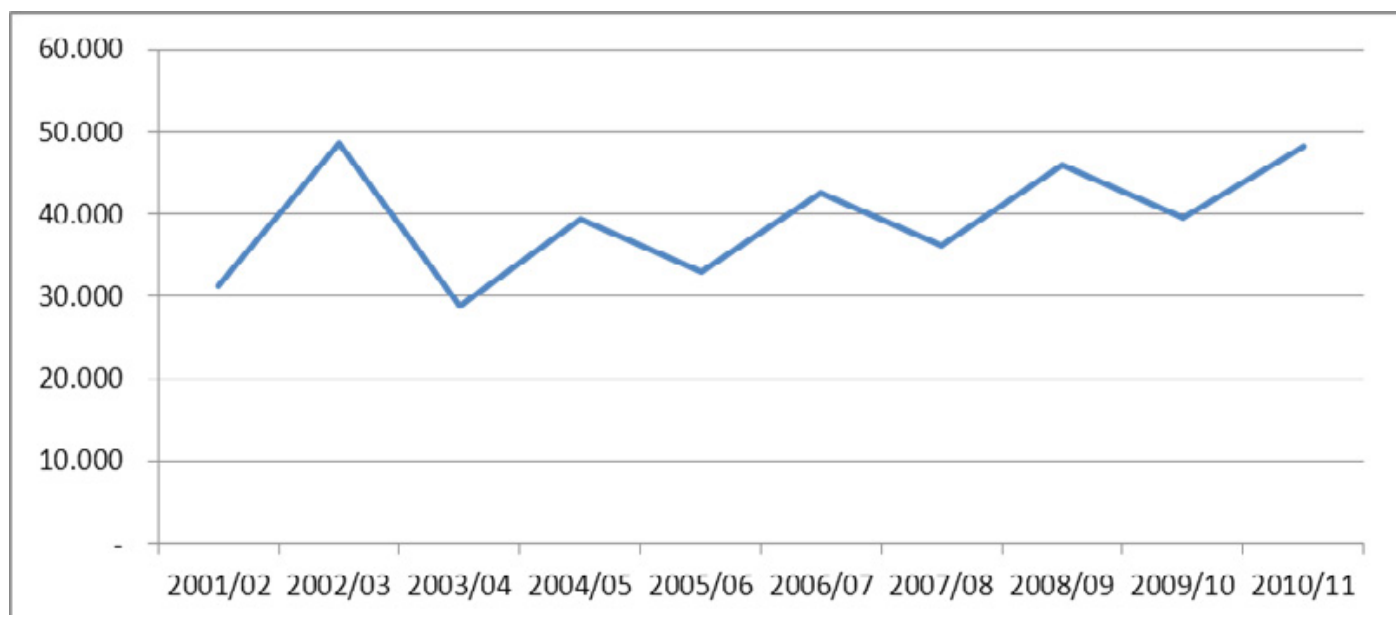

Gráfico 1 - Evolução da produção brasileira de café - Período: 2001/02 a 2010/11

Fonte: CONAB, 2011 (elaboração nossa)

Aárea cultivada em 2010/11 foi de 2.076,6 mil hectares, 0,8\% menor que o biênio anterior e $4,7 \%$ menor que 2001/02. Porém, a adoção de novas técnicas de manejo, os diversos tipos de poda e a renovação gradual das lavouras têm contribuído para o aumento da produtividade. Em $2010 / 11$, a produtividade foi de 23,16 sacas por hectare, $22,8 \%$ superior ao biênio anterior e $61,3 \%$ maior que $2001 / 02$.

Segundo a CONAB (2011), a expectativa para o biênio 2011/12 é que a produção de café seja de 43,54 milhões de sacas de 60 quilos do produto beneficiado, com redução de 9,5\%, comparativamente com a obtida na temporada anterior. Já a área plantada estimada é de $2.282,1$ mil hectares, 0,31\% inferior ao biênio 2010/11.

\subsection{Análise descritiva dos dados}

Assim como a produção, os preços no mercado futuro e à vista também oscilam muito. A Figura 2 demonstra o comportamento dos preços médios mensais cotados no mercado futuro e os preços à vista nos meses dos vencimentos dos contratos futuros, ambos em dólares americanos, para o período compreendido entre março de 2005 a maio de 2011.

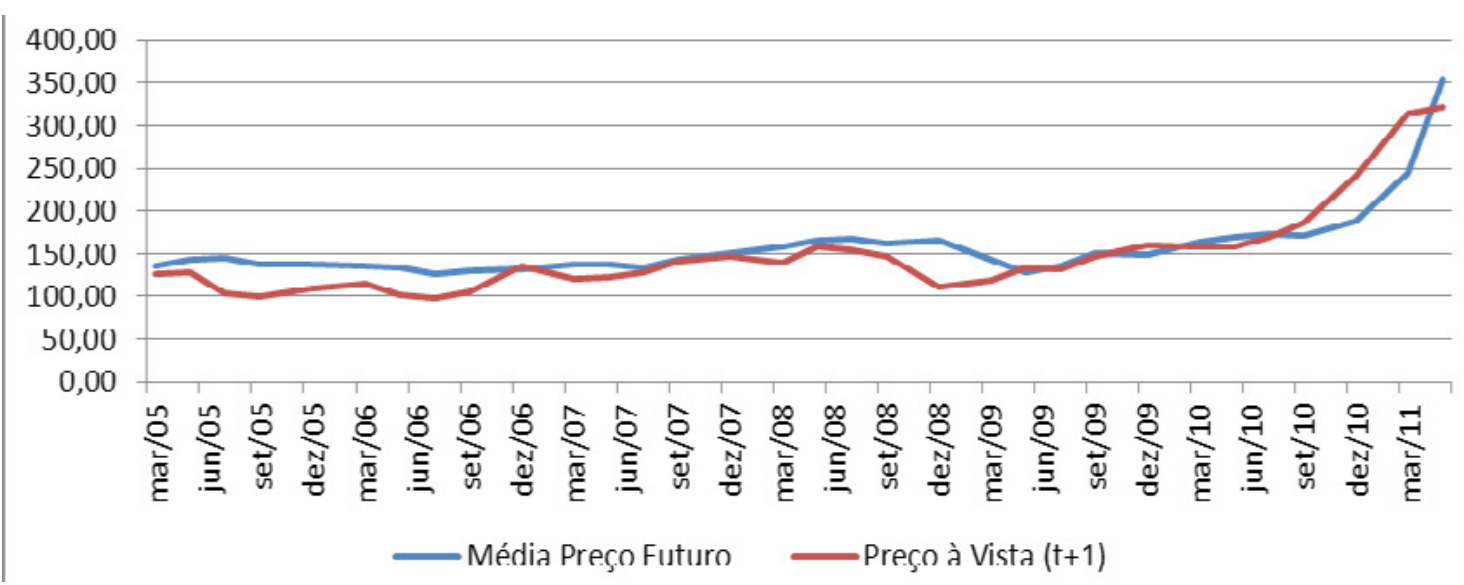

Gráfico 2 - Comportamento dos preços médios futuros e preços à vista nos meses dos vencimentos dos contratos futuros, em dólares americanos - Período: 2005 a 2011.

Fonte: os autores, 2011. 
A primeira abordagem da análise é uma visão puramente descritiva dos valores dos Preços Futuro (PF) e dos Preços à Vista (PV) do Café Arábica. A Tabela 1 apresenta estes dados e permite uma avaliação.

Tabela 1 - Estatísticas descritivas para o Preço Futuro - PF e Preço à Vista - PV

\begin{tabular}{c|c|c}
\hline Estatística Descritiva & Preço Futuro & Preço à Vista \\
\hline \hline Média & 157,74 & 147,95 \\
Máximo & 353,45 & 321,02 \\
Mínimo & 126,59 & 97,51 \\
Desvio Padrão & 42,58 & 53,01 \\
Assimetria & 3,39 & 2,17 \\
Curtose & 15,49 & 7,43 \\
Jarque-Bera & 269,52 & 51,57 \\
p-value & 0 & 0 \\
\hline
\end{tabular}

Fonte: os autores, 2011.

De acordo com a Tabela 1, é possível verificar que a média do PF ficou em torno de US\$ 157,74 , com desvio padrão de US\$ 42,58, enquanto seu valor máximo foi de US\$ 353,45 e valor mínimo US\$ 126,59. O coeficiente de assimetria 3,39 revela uma distribuição assimétrica positiva, e o coeficiente de curtos 15,49 sugere uma distribuição leptocúrtica. Quanto à verificação de normalidade na série, o valor de 269,52 para o teste Jarque Bera, associado a seu $p$-value 0,00, demonstra que o PF não segue uma distribuição normal.

Na Tabela 1, ainda é possível observar que a média do PV ficou em torno de US\$ 147,95 , com desvio padrão de US\$ 53,01, enquanto seu valor máximo foi de US\$321,02 e valor mínimo US\$ 97,51. O coeficiente de assimetria 2,17 revela uma distribuição assimétrica positiva, e o coeficiente de curtose 7,43 sugere uma distribuição leptocúrtica. Quanto à verificação de normalidade na série, o valor de 51,57 para o teste Jarque Bera, associado a seu $p$-value 0,00 , demonstra que o PV não segue uma distribuição normal.

\subsection{Análise da estacionariedade dos dados}

Para que seja identificada formalmente a presença ou não de tendência nas séries históricas das variáveis Preços Futuros (PF) e Preços à Vista (PV), realizou-se o teste ADF (DICKEY; FULLER, 1979 e 1981), visando-se a detectar a presença de raízes unitárias. As hipóteses estão descritas na seção três, e os resultados das análises são apresentados na Tabela 2.

Tabela 2: Resultado do teste ADF para as variáveis em nível

\begin{tabular}{|c|c|c|c|c|c|c|c|c|}
\hline \multirow{2}{*}{ Variável } & \multicolumn{2}{|c|}{$\begin{array}{l}\text { Sem Tendên- } \\
\text { cia }\end{array}$} & \multicolumn{2}{|c|}{$\begin{array}{c}\text { Com Tendên- } \\
\text { cia } \\
\end{array}$} & \multicolumn{2}{|c|}{ ADF Crítico (5\%) } & \multirow{2}{*}{$\begin{array}{c}\text { Deci- } \\
\text { são } \\
\left(H_{0}\right)\end{array}$} & \multirow{2}{*}{ Classificação } \\
\hline & DF & ADF & DF & ADF & $\begin{array}{l}\text { Sem } \\
\text { Tend }\end{array}$ & $\begin{array}{l}\text { Com } \\
\text { Tend }\end{array}$ & & \\
\hline PF & 5,25 & 2,31 & 3,92 & 0,75 & \multirow{2}{*}{$-2,98$} & \multirow{2}{*}{$-3,59$} & Aceitar & Não Estacionário \\
\hline PV & 1,77 & 1,16 & 0,24 & $-0,93$ & & & Aceitar & Não Estacionário \\
\hline
\end{tabular}

Fonte: os autores, 2011.

Nota: Testes realizados utilizando-se 5 defasagens 
Os resultados presentes na Tabela 2 evidenciam que, sob a hipótese nula de presença de raízes unitárias com distribuição, segundo Fuller (1976), para valores críticos da estatística ADF a 5\%, deve-se aceitar a hipótese nula de não estacionariedade para as variáveis Preços Futuros (PF) e Preços à Vista (PV) do café, ou seja, as séries históricas das variáveis em questão são não estacionárias em nível e apresentam tendência. Tais resultados atendem aos pré- requisitos para a operacionalização do teste de cointegração de Johansen, o qual requer que os dados sejam não estacionários.

\subsection{ANÁLISE DA EFICIÊNCIA DO MERCADO DE CAFÉ}

Uma vez que as séries históricas Preços Futuros e Preços à Vista são não estacionárias, é possível avaliar a eficiência do mercado de café brasileiro por meio do teste de cointegração de Johansen. Se as séries são cointegradas, ou seja, se elas mantêm um relacionamento de equilíbrio em longo prazo, há indícios da eficiência de mercado.

As hipóteses testadas estão descritas na seção 3 deste trabalho, e os resultados do teste de Johansen podem ser observados na Tabela 3.

Tabela 3 - Teste de cointegração de Johansen para as variáveis PF e PV.

Amostra: 32 observações
Número de observações in
Séries: PV e PF
Intervalo dos Lags: 1 até 5
Nível de significância 0,05

Número de relações cointegrantes por modelo

\begin{tabular}{|c|c|c|c|c|c|}
\hline Tendência & Nenhuma & Nenhuma & Linear & Linear & Quadrática \\
\hline \multirow{2}{*}{ Teste } & S/ Intercepto & Intercepto & Intercepto & Intercepto & Intercepto \\
\hline & S/ Tendência & S/ Tendência & S/ Tendência & Tendência & Tendência \\
\hline Traço & 0 & 0 & 0 & 0 & 1 \\
\hline Max-Eig & 0 & 0 & 0 & 0 & 1 \\
\hline \multicolumn{6}{|c|}{ *Valores Críticos baseados em MacKinnon-Haug-Michelis (1999) } \\
\hline \multicolumn{6}{|c|}{ Critério de informação por Rank e Modelo } \\
\hline Tendência & Nenhuma & Nenhuma & Linear & Linear & Quadrática \\
\hline Rank ou & S/ Intercepto & Intercepto & Intercepto & Intercepto & Intercepto \\
\hline №, de RC & S/ Tendência & S/ Tendência & S/ Tendência & Tendência & Tendência \\
\hline \multicolumn{6}{|c|}{ Log Probabilidade por Rank (fileiras) e Modelos (colunas) } \\
\hline 0 & -197.7793 & -197.7793 & -195.3580 & -195.3580 & -193.4021 \\
\hline 1 & -195.3393 & -189.8781 & -189.7805 & -185.7062 & -183.7718 \\
\hline 2 & -194.1703 & -188.5950 & -188.5950 & -183.7044 & -183.7044 \\
\hline \multicolumn{6}{|c|}{ Critério de Informação de Akaike por Rank (fileiras) e Modelo (colunas) } \\
\hline 0 & 16.75225 & 16.75225 & 16.71985 & 16.71985 & 16.72324 \\
\hline 1 & 16.87226 & 16.52908 & 16.59850 & 16.36202 & $16.29014 *$ \\
\hline 2 & 17.09003 & 16.81500 & 16.81500 & 16.59264 & 16.59264 \\
\hline \multicolumn{6}{|c|}{ Critério de Schwarz por Rank (fileiras) e Modelo (colunas) } \\
\hline 0 & 17.72002 & 17.72002 & 17.78439 & 17.78439 & 17.88456 \\
\hline 1 & 18.03358 & 17.73879 & 17.85660 & 17.66850 & 17.64501* \\
\hline 2 & 18.44490 & 18.26665 & 18.26665 & 18.14107 & 18.14107 \\
\hline
\end{tabular}

Fonte: os autores, 2011. 
Conforme os resultados da Tabela 3, verifica-se, ao nível de 5\%, que existem pelo menos dois vetores de cointegração, um na estatística do Traço e outro na estatística do Máximo Eigenvalor, devendo-se rejeitar a hipótese nula em favor da hipótese alternativa, ou seja, os Preços Futuros e os Preços à Vista são cointegrados, em outras palavras, há evidências da eficiência do mercado brasileiro de café.

A cointegração é apenas uma condição necessária para a eficiência de mercado, mas não é o suficiente. Ainda é preciso saber se os preços futuros no período atual $\left(F_{t}\right)$ são estimadores não viesados dos preços à vista no período futuro $(t+1)$. Assim sendo, em uma regressão do preço à vista em função do preço futuro, os coeficientes da equação não devem diferir significativamente de $\alpha=0$ e $\beta=1$, em outras palavras, os preços futuro atuais serão bons previsores dos preços à vista nos períodos futuros. $O$ intercepto $(\alpha)$ igual à zero indica neutralidade ao risco, e o coeficiente angular $(\beta)$ igual a um indica que toda informação disponível foi incorporada ao preço futuro.

Dessa maneira, o passo seguinte consiste em realizar uma regressão do Preço à Vista em função do Preço Futuro e, em seguida, analisar seus coeficientes estimados. Como os resultados da Tabela 2 indicaram a presença de raiz unitária nas séries temporais, foi necessária a transformação das mesmas até se tornarem estacionárias, o que foi obtido por meio do logaritmo das variáveis. A Tabela 4 apresenta os principais resultados da regressão.

Tabela 4 - Regressão do Log. do Preço à Vista em função do Log. do Preço Futuro

\begin{tabular}{cccc}
\hline & Coeficiente & Teste t & p-value \\
\hline Constante $(\alpha)$ & 1,96 & 6,39 & 0,00 \\
Log_Preço a Vista $(\beta)$ & 0,621469 & 10,00 & 0,00 \\
\hline$R^{2}=0,77$ & & &
\end{tabular}

$\mathrm{R}^{2}=0,77$

$\mathrm{DW}=1,18$

$F(1,30)=100,8 p$-value $=0,00$

Fonte: os autores, 2011.

A partir da Tabela 4, verifica-se que, diante do período utilizado na amostra dos preços do café, os coeficientes $\alpha$ e $\beta$ são significativos a 0,001 , rejeitando-se a hipótese nula de que seus valores sejam iguais à zero. Contudo, para que os preços futuros cotados no momento atual sejam previsores não viesados dos preços à vista no futuro, é condição necessária que $\alpha=0$, o que não aconteceu. Isso indica a presença de um viés embutido nos preços futuros, ou seja, há evidências da existência de um prêmio associado ao risco. A eficiência de mercado na forma fraca exige, ainda, que $\beta=1$, o que também não foi constatado, indicando que há evidências estatísticas de que os preços no mercado futuro não incorporaram todas as informações disponíveis. Como resultado, há indícios de que o mercado futuro do café não se apresenta eficiente, ou seja, os preços futuros no período atual não são previsores não viesados do preço à vista esperado no futuro.

Ainda que com objetivos diversos, outros estudos testando a cointegração envolvendo a commoditie café arábica já foram realizados. Moss e Braga (2006), por exemplo, aplicaram o teste de cointegração de Engle e Granger com o objetivo de verificar se o preço do café brasileiro, pago ao produtor e pago pelo consumidor, relaciona-se no longo prazo. Para isso, analisaram o período compreendido entre janeiro de 1996 a abril de 2005. Os resultados apresentados não permitem rejeitar a hipótese de que os preços do café pago ao produtor e pago pelo consumidor sejam cointegrados e sugerem que o mercado brasileiro de café está funcionando adequadamente, com rápida difusão de informações, permitindo mecanismos de arbitragem, e que, dessa forma, alguns setores da cadeia obtenham vantagem desse fato. Isso indica não só a hipótese de 
eficiência de mercado, mas também a presença de um viés na composição do preço.

Valente e Braga (2006), por sua vez, tinham como objetivo avaliar o comportamento dos preços futuros do café negociado no mercado brasileiro pela BM\&F e nos Estados Unidos da América pela NYBOT, no período de janeiro de 1994 a outubro de 2005. Utilizando o teste de Engle e Granger e o teste de causalidade de Granger, os resultados apontam uma relação de equilíbrio, em longo prazo, entre os preços futuros da BM\&F e NYBOT, indicando que a bolsa internacional pode ser considerada uma boa referência para os preços domésticos e vice-versa. Resultado semelhante também foi alcançado por Cunha et al. (2010), que objetivaram verificar a presença de cointegração nos preços do café arábica praticados pelo Brasil e demais principais países produtores com os preços praticados no mercado internacional.

Já Melo, Lima e Moraes (2006) tinham o mesmo objetivo deste trabalho em testar a eficiência de mercado para as commodities boi gordo, açúcar cristal, milho e café arábica, utilizando o teste de cointegração de Engle e Granger. Os períodos analisados para cada mercadoria foram: boi gordo, de junho de 2000 a junho de 2004; açúcar cristal, de março de 2000 a junho de 2004; milho, de agosto de 2004 a fevereiro de 2006; e café, de março de 2000 a junho de 2004. De início, o teste ADF apontou estacionariedade entre os preços futuros e à vista do café, não havendo, dessa forma, cointegração. Contudo, para as demais commodities, as séries de preços indicaram evidências da hipótese de eficiência de mercado e não apontaram indícios de viés no longo prazo.

Amado e Carmona (2003) verificaram a eficiência de mercado na forma fraca para as commodities agrícolas brasileiras café arábica e açúcar cristal no período entre janeiro de 2000 a março de 2003 a fim de verificar se os preços futuros poderiam ser considerados estimadores não viesados para os preços spot de um a três meses. Constataram que os preços futuros do açúcar não podem ser considerados bons estimadores para o preço spot nos prazos de dois e três meses, entretanto, são considerados eficientes na forma fraca para um mês. No caso do café, para todos os vencimentos, o teste de regressão mostrou-se cointegrado, indicando que os preços futuros podem ser utilizados como estimadores para os preços à vista; mas também demonstraram indícios de viés nos preços e, portanto, o mercado de café não pode ser considerado eficiente na forma fraca.

Os resultados encontrados no presente estudo corroboram aqueles encontrados por Amado e Carmona (2003) para a commoditie café arábica, mas refutam a hipótese da não existência de cointegração alcançada por Melo, Lima e Moraes (2006).

Apenas esses três trabalhos testaram, além da existência de cointegração, os parâmetros $\alpha=0$ e $\beta=1$, que verificam a não presença de viés e a eficiência de mercado na forma fraca. Apesar da ressalva apresentada por Melo, Lima e Moraes (2006) de não existência de cointegração, os resultados apontam um indício de que o café arábica possui características diferentes das commodities boi gordo, milho e açúcar cristal.

\section{CONSIDERAÇÕES FINAIS}

O objetivo deste artigo foi testar a eficiência na forma fraca do mercado futuro do café arábica cotado na BM\&F para saber se seus preços são previsores não viesados do preço à vista esperado no futuro. As variáveis coletadas Preços Futuros e Preços à Vista compreendem o período entre janeiro de 2005 a maio de 2011. Para atingir o objetivo proposto, foram utilizados os testes de raízes unitárias ADF de Dickey e Fuller e de cointegração de Johansen.

Os resultados apresentados para o teste ADF indicaram a aceitação da hipótese nula de não estacionariedade para as variáveis Preços Futuros (PF) e Preços à Vista (PV), ou seja, apresentaramse não estacionárias em nível e com tendência. Já o teste de cointegração de Johansen constatou a 
existência de vetores de cointegração na estatística do Traço e na estatística do Máximo Eigenvalor, o que evidenciou um relacionamento de longo prazo entre os preços futuro e à vista.

Porém, a existência de um relacionamento de longo prazo entre os preços cotados no mercado futuro e os preços à vista representa apenas uma condição para a eficiência de mercado, mas não é o suficiente. Para saber se os preços futuros são previsores não viesados dos preços à vista no período futuro, foi necessário testar os parâmetros da regressão. Assim, o intercepto $\alpha$ deveria ser zero e o coeficiente angular $\beta$ deveria ser igual a 1 . O intercepto zero estaria indicando a não presença de um prêmio ao risco, ao passo que o coeficiente angular igual a um indicaria que toda informação disponível foi incorporada ao preço futuro, de acordo com a forma fraca de eficiência concebida por Fama (1970).

Para a realização do teste dos parâmetros da regressão, as séries históricas de preços foram logaritmizadas pelo fato de serem não estacionárias. Esse teste não confirmou que $\alpha=$ 0 e $\beta=1$. De acordo com os resultados apresentados, foi possível aferir que o mercado futuro brasileiro do café arábica apresenta indícios estatísticos de não eficiência, bem como da presença de um viés, indicando a existência de um prêmio incorporado ao risco.

Entretanto, é possível que outros estudos que visem testar a eficiência de mercado do café possam chegar a resultados diferentes. A literatura é prova disso, ora afirmando, ora rejeitando os resultados. Como os preços das commodities agrícolas são fortemente influenciados por diversos fatores, assim como as séries históricas de preços, podem apresentar comportamentos diferentes, dependendo do período analisado. Além disso, pelo fato de que a eficiência de mercado pode ser obtida com a utilização de diferentes técnicas econométricas, é possível que outros estudos cheguem a resultados diferentes. De qualquer modo, independente dos resultados alcançados, estudos testando a eficiência de mercado sempre mantêm sua importância para a compreensão do seu funcionamento. Assim, essa temática deixa espaços para pesquisas futuras, com esta ou outras commodities. 


\section{REFERÊNCIAS}

AMADO, Carlos F. Pedrosa; CARMONA, Charles U. de Montreuil. Eficiência dos Mercados Futuros: um estudo utilizando teste de cointegração para commodities agrícolas. In: XXVII EnANPAD, 27. 2003, Atibaia. Anais... Atibaia: 2003. 1 CD-ROM.

Análise da Eficiência dos Mercados

Futuros Agrícolas Brasileiros: uma análise da eficiência dos mercados futuros agrícolas brasileiros. In: IV Encontro Brasileiro de Finanças, 4. 2004, Rio de Janeiro. Anais... Rio de Janeiro: 2004. Disponível em: <http:// bibliotecadigital.fgv.br/ocs/index.php/ ebf/4EBF/paper/view/1522/641>. Acesso em: 05 jul. 2011.

AMARAL, Carlos Antônio Lopes Vaz. Derivativos: o que são e a evolução quanto ao aspecto contábil. Revista Contabilidade e Finanças, São Paulo, v. 1, n. 32, p. 71-80, mai - ago. 2003.

BARROS, Ligia C; LOPES, Christianne C. V de Melo. Uma Análise da Evidenciação dos Derivativos nas Companhias Energéticas sob a Ótica da Instrução CVM n. 235 de 23/03/95. Revista de Contabilidade do Mestrado em Ciências Contábeis da UERJ, Rio de Janeiro, v. 11, n. 1, p. 1-12, jan./jun. 2006.

BESSADA, Octavio; BARBEDO, Claudio; ARAÚJO, Gustavo. Mercado de Derivativos no Brasil. 2. ed. Rio de Janeiro: Record, 2007.

CARVALHO, Luciano F; GIACHERO, Osvaldo S; RIBEIRO, Kárem C. de Souza. A Hipótese da Eficiência de Mercado: análise dos casos AMBEV e Submarino. In: Simpósio de Excelência em Gestão Tecnológica, 4. 2007, Resende. Anais... Resende: 2007. Disponível em: <http://www. aedb.br/seget/artigos07/1149_1149_Artigo3_ Karen_Seget_Autores.pdf $>$. Acesso em: 18 jun. 2011.

COMPANHIA NACIONAL DE
ABASTECIMENTO. Acompanhamento da Safra Brasileira Café Safra 2011segunda estimativa, maio/2011. Brasília: CONAB, 2011. Disponível em: <http://www. conab.gov.br/OlalaCMS/uploads/ arquivos/11_05_10_09_04_16_boletim cafe_-_maio_-_2011..pdf $>$. Acesso em: 05 jun. 2011.

CUNHA, Dênis A. et al. Integração e transmissão de preços no mercado internacional de café arábica. Revista de Economia e Sociologia Rural, Piracicaba, v. 48, n. 4, p. 515-545, out./dez. 2010.

DICKEY, David.; FULLER, Wayne. Distribution of the estimators for autoregressive time series with a unit root. Journal of the American Statistical Association, n. 366, v. 74, p. 427-431, 1979.

A likelihood ratio statistics for autoregressive time series with a unit root. Econométrica, n. 4, v. 49, p. 1057-1072, 1981.

FAMA, Eugene F. Efficient Capital Markets: A Review of Theory and Empirical Work. The Journal of Finance, New York, v. 25, n. 2, p. 383-417, may 1970. Disponível em: < http://finance.martinsewell.com/stylizedfacts/volatility/Fama1970.pdf>. Acesso em: 18 jun. 2011.

FIGUEIREDO, Antonio Carlos. Introdução aos Derivativos. São Paulo: Pioneira Thomson Learning, 2002.

FULLER, Wayne Artur. Introduction to the statistical time series. Wiley-Interscience, 1976.

GUJARATI, Damodar. N. Econometria básica. Rio de Janeiro: Elsevier, 2006.

HULL, John. Fundamentos dos Mercados Futuros e de Opções. 4. ed. São Paulo: BM\&F, 2005.

JOHANSEN, Soren. Statistical analysis of 
cointegration vector. Journal of Econometric Dynamic and Control, v. 12, p. 231-254, 1988.

Estimation and hypothesis testing of co integration vectors in Gaussian vector autoregressive models. Econometrica, [S.I.], v. 59, n. 6, p. 1551-1580, 1991.

Likelihood-based inference in co integrated vector autoregressive models. Oxford: University of Oxford, 1995.

JOHANSEN, Soren; JUSELIUS, Katarina. Maximun likelihood estimation and inference on cointegration, with application to the demand for money. Oxford Bulletin of Economics and Statistics, [S.I.], v. 52, p. 169210, 1990

JUNG, Carlos Fernando. Metodologia Científica: ênfase em pesquisa tecnológica. 3. ed. 2003. Disponível em: <http://www.jung. pro.br>. Acesso em: $11 \mathrm{dez} .2010$.

MALKIEL, Burton G. The Efficient Market Hypothesis and it's Critics. Princeton University CEPS Working Paper, n. 91, april 2003. Disponível em: <http://www. princeton. edu/ ceps/workingpaper/91malkiel.pdf >. Acesso em: 18 jun. 2011.

MARQUES, P.V.; MELLO, P.C. Mercados Futuros de Commodities Agropecuários: exemplos e aplicações aos mercados brasileiros. São Paulo: Bolsa de Mercadorias \& Futuros, 1999.

MELO, André de Souza; LIMA, Ricardo Chaves; MORAES, André Steffens. Análise da Eficiência dos Mercados Futuros de Commodities Agrícolas Brasileiras Utilizando Co-integração. Sociedade Brasileira de Economia, Administração e Sociologia Rural, 2006. Disponível em: <http://www.sober.org.br/ palestra/5/532.pdf>. Acesso em: 05 jul. 2011.

MOSS, Sara R.; BRAGA, Marcelo J. Integração dos preços de café no Brasil: o repasse de verbas aos cafeicultores brasileiros. In: CONGRESSO DA SOCIEDADE BRASILEIRA DE ECONOMIA E SOCIOLOGIA RURAL, 44., 2006, Fortaleza.
Anais... Fortaleza, 2006.

QMS - Quantitative Micro Software. E-Views 5 User's Guide. Irvine, CA: QMS, 2004.

VALENTE, Marcelo L. Campos; BRAGA, Marcelo J. Causalidade e cointegração no mercado de café entre a BM\&F e NYBOT. In: CONGRESSO DA SOCIEDADE BRASILEIRA DE ECONOMIA E SOCIOLOGIA RURAL, 44., 2006, Fortaleza. Anais... Fortaleza, 2006.

WESTON, J. Fred; BRIGHAM, Eugene. Fundamentos da Administração Financeira. 10. ed. Tradução Sidney Stancatti. São Paulo: Makron Books, 2000.

WONNACOTT, Paul; WONACOTT, Ronald. Economia. Trad. Yeda R. Crusius e Carlos A. Crusius. São Paulo: McGraw-Hill do Brasil, 1982. 